original investigations. He wrote a "Book of Almanacs," with an Index of Reference, by which the Almanac may be formed for every year up to A.D. 2000, with means of finding the day of the new moon from B.C. 2000 to A.D. 2000. He was also secretary and member of the Council of the Rryal Astronomical Society for many years. He and his son, George De Morgan, also a mathematician of great promise, whose untimely death will be remembered, took the most active part in the foundation of the London Mathematical Society, of which he was the first president. Prof. De Morgan will be buried on Thursday, the $23 \mathrm{rd}$, at Kensal Green, but his memory will long be cherished among a large circle of attached and admiring friends.

ARTHUR C. RANYARD

\section{PAPERS ON IRON AND STEEL}

\section{IV.-The Bessemer Process (continued).}

THE magnificent shower of sparks which accompanies the turning over of the converter is easily explained. The blast has, of course, to be maintained during this turning over, until the whole of the melted material is clear of the openings through which the blast is forced. As these cover a considerable area at the bottom of the converter, the edge of the liquid passes them successively, and at the moment of thus passing the blast cuts the surface of the melted matter almost horizontally. But what is this melted matter? It is a pool of iron, on the top of which is floating a thick scum of silicate of iron, \&c.-the "cinder." I use the term "silicate of iron" only in an approximate sense, as I doubt whether the silica is completely oxidised.

My reasons for doubting it are that the particles which are driven out of the converter by the blast are, to some extent, explosive, they are seen to burst with brilliant coruscations which are partly due to further oxidation; and when the granules which shower upon the floor are examined in the microscope, they present a very curious appearance. They are minute hollow spherules, miniature bomb-shells, varying considerably in diameter from onetenth of an inch to one-fiftieth and less in diameter. The largest are more or less broken, commonly of a basin shape, shown in Figs $I$ and 2.*

The smaller spherules are for the most part perforated. My friend, Mr. Joseph Bragg, who has carefully examined these, and to whom I am indebted for the drawings from which the engravings are copied, says, "I can hardly satisfy myself that any are quite without apertures, though some have no distinct round holes as most have, but in these cases there are minute openings between and under the welded scales or plates which often cover the spherules, giving them a rough surface." Conglomerate groups of these spherules, such as are shown in Figs. $3^{*}$ and 4 , are very common, and some are attached to irregular lumps of cinder, as shown by the right-hand fragment on Fig. 3 . A few are pear-shaped (see Fig. 4). On the right of these pear-shaped specimens are shown some of the smaller spherules in which the perforations are less evident. In the smallest, as the agglomerated and attached specimens (Fig. 3), the perforations are very obscure or doubtful.

Sir Samuel Baker, in his "Nile Tributaries of Abyssinia," describes some natural products due to a similar action on a vastly larger scale, viz., the volcanic eruption of a flood of gaseous matter through fused silicates. He says, "Rows of broken hills, all of volcanic origin, broke the flat plain. Conical tumuli of volcanic slag here and there rose to the height of several hundred feet. We entered a dead level plain of orange-coloured sand, surrounded by pyramidal hills; the surface was strewn with objects resembling cannon shot and grape of all sizes, from a $32-$ pounder downwards; the spot looked like the old battle-

* Figs r, 2, and 3 will be found in last week's number of Natura, p. 320 fields of some infernal region. . . . I dismounted to examine the Satanic bombs and cannon shot. Many of them were as perfectly round as though cast in a mould, others were egg-shaped, and all were hollow. With some difficulty I broke them, and found them to contain a bright red sand; they were, in fact, volcanic bombs that had been formed by the ejection of molten lava to a great height from active volcanoes; these had become globular in falling, and having cooled before they reached the earth, they retained their forms as hard spherical bodies precisely resembling cannon shot. The exterior was brown, and appeared rich in iron. The smaller specimens were the more perfect spheres, as they had cooled quickly, but many of the heavier masses had evidently reached the earth when only half solidified, and had collapsed in falling. The sandy plain was covered with such vestiges of volcanic action, and the infernal bombs lay as imperishable relics of a hailstorm such as may have destroyed Sodom and Gomorrah." To a Lilliputian traveller about an inch and a quarter high the floor of a Bessemer shop would present about the same aspect as this volcanic plain presented to Sir Samuel Baker, and would appear on about the same scale relative to the traveller's own dimensions.
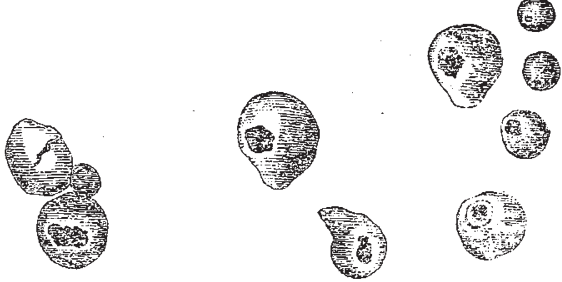

FIG. 4.

It may have been remarked that in the above I have never used the word "slag," which in chemical works is usually applied to the separated silicate of iron, \&c., however it may have been separated. I have called it "cinder," in accordance with the nomenclature of the workshop, for in the use of these terms, slag and cinder, the workshop is more learned than the University, even in the matter of etymologies, which occupies so absorbing an amount of University attention.

Whenever the silicate is separated by fusion or the direct action of the fire he calls it "cinder," when it is squeezed out from a bloom or pile by the blows of the hammer he calls it "slag." Now the Scandinavian name of fire refuse or dross is sinner, the German for the same is sinter. The Scandinavian for a blow is slag, the German schlag. I have observed with much interest the constancy with which the workman adheres to the strictly etymological signification of these words, while learned writers uttes ly confound them. Of course the workmen are unacqua: nted with their origin, nor have I ever seen their distingetive etymologies pointed out by anybody else. They afford an interesting illustration of the technical continuity of modern English with its ancient Scandinavian basis. Our metal workers, like our sailors, still speak the strong tongue of the old Norseman. There are scientific as well as etymological reasons for the distinction between cinder and slag, and therefore I adopt the workmen's phraseology.

W. Mattieu WrLliams

\section{SCIENCE IN GOVERNMENT WORKSHOPS}

THERE seems to be a singular antagonism between science and officialism. The Government has undertaken more than one special manufacture, and not without a certain measure of success, but even the best of Government factories are tainted with some 